\title{
CUSTO DO SERVIÇO DE ATENDIMENTO ÀS VÍTIMAS NO CORPO DE BOMBEIROS DE TOLEDO - PARANÁ
}

Arlei Bieger ${ }^{1}$

\begin{abstract}
RESUMO
O presente trabalho busca identificar o custo do serviço de atendimento às vítimas socorridas pelo Corpo de Bombeiros de Toledo - Paraná, no ano de 2019. Observa-se que a questão do custo para se manter o serviço disponível ininterruptamente, acaba em segundo plano, mas nunca à sombra da legalidade e do zelo exigido. O referencial teórico abrange a Contabilidade Pública, Despesa Pública e informações da organização em questão. Para o período definido realizou-se o levantamento de dados sobre vítimas atendidas, gastos com materiais, veículos, serviços e recursos humanos, envolvendo as despesas demandadas sob gestão do Corpo de Bombeiros para viabilizar o serviço de atendimento às vítimas. Independentemente do resultado contábil obtido salienta-se que o trabalho visa colaborar com a gestão do órgão público, pela disponibilização de informações que auxiliem na tomada de decisões pertinentes ao êxito de tal serviço. Identificou-se ao final do estudo a composição do custo total do serviço e o custo médio por vítima atendida no ano de 2019. Entende-se que para o âmago do serviço prestado pelo Corpo de Bombeiros, o melhor resultado não é mensurável pela contabilidade, pois ao final do "exercício" o que se deseja é a preservação da vida humana.
\end{abstract}

Palavras-chave: Custo; Atendimento às Vítimas; Corpo de Bombeiros; Despesa.

\footnotetext{
1 1 Sargento do Corpo de Bombeiros Militar do Paraná. Bacharel em Administração pela UTFPR, Especialista em Gestão de Negócios e Logística pela UTFPR, em Direito Militar Contemporâneo pela UTP, em Gestão Pública pela UCAM, em Contabilidade Pública pela FAVENI. Mestre em Desenvolvimento Regional e Agronegócio pela UNIOESTE. Email: arlei.bieger@bm.pr.gov.br.
} 


\title{
THE COST OF ASSISTANCE TO VICTIMS SERVICES AT THE FIRE DEPARTMENT OF TOLEDO - PARANÁ
}

\begin{abstract}
The purpose of this paper is to determine the cost of the assistance to the victims rescued by the Fire Department of Toledo - Paraná, during the year of 2019. It was observed that the issue of the cost to maintain the service continuously available ends up in the background, but never aside from the law and the zeal required. The theoretical reference covers data from the Public Accounting, Public Expenditure and information from the organization. For this specified period, the data collected covered information about the victims assisted, expenses with material, vehicles, service and human resources, involving the expenses required under the management of the Fire Department in order to facilitate the service of assistance to victims. Regardless of the accounting result obtained, the aim of this paper it to collaborate with the management of the public agency, through the disclosure of information that may help with the process of making decisions that are sensible to the success of such service. At the end of the study, it was possible to trace the composition of the total cost of the service and the average cost by victim assisted in 2019. Finally, it was understood that at the core of the service provided by the Fire Department, the best result is not measurable in numbers, since the final intent is the preservation of human lives.
\end{abstract}

Key Words: Cost; Assistance to victims; Fire Department; Expenses. 


\section{INTRODUÇÃO}

O crescimento e desenvolvimento dos países nos tempos atuais trazem na bagagem grandes benefícios à sociedade, mas também, e em consequência disso, trazem o ônus da expansão geográfica e econômica, o qual não é desejado, nem tampouco idealizado em uma sociedade de relações harmonizadas. Em um país onde grande parte da população depende do setor público para ter socorro e acesso à saúde, esse ônus social tem demonstrado grande relevância contábil, entre outros reflexos.

Dentre essas consequências negativas, uma de suas faces, acarreta um viés de incolumidade social, ou seja, toda evolução econômica acarreta demandas periféricas para sua sustentação, e indiferente de sua origem, alguns problemas acabam por afetar a harmonia social. Nesse ínterim, encontram-se as vítimas de traumas físicos diversos, seja no trânsito urbano, candidato a grande vilão, ou nos demais ambientes e situações em que as pessoas se encontrem, em suas rotinas diárias de trabalho e vivência particular.

Visando a mensuração econômica dos efeitos de uma dessas mazelas que acometem a sociedade contemporânea, o estudo pretende verificar o custo de atendimento às vítimas de traumas físicos, socorridas por uma unidade de um órgão Estadual de Segurança Pública, em um estado brasileiro pioneiro na estruturação do atendimento pré-hospitalar, o Paraná. Para tanto foi delimitado o município de Toledo, localizado na região Oeste do Estado, ente federativo no qual foi implantado o Sistema Integrado de Atendimento a Traumas e Emergências (SIATE) no ano de 1995, fator que desencadeou grande desenvolvimento no serviço de socorro às vítimas, prestado pelo Corpo de Bombeiros Militar do Paraná.

Neste ínterim, o problema a que se busca resposta neste estudo, envolve a mensuração do custo do serviço de atendimento pré-hospitalar às vítimas de traumas ou outras adversidades, nos serviços demandados pelo 
Corpo de Bombeiros Militar do município de Toledo - PR. Para delimitar um período de estudo e análise de dados, foi definido o ano de 2019 como intervalo temporal, sendo que a pesquisa busca levantar o máximo de dados disponíveis pertinentes ao assunto, registrados no período em questão.

Há que se ressaltar que o questionamento não busca respostas que possam demonstrar o viés da viabilidade econômica ou de custo-benefício, de forma alguma, pois o bem a ser resguardado com tal prestação de serviço, ou seja, a vida humana, não tem mensuração monetária conhecida, ao menos no "mundo perfeito".

Assim, o objetivo principal é conhecer o custo do serviço prestado pelo Corpo de Bombeiros de Toledo, no que tange ao atendimento às vítimas inclusas nas ocorrências registradas no período definido. Para compor tal informação, buscou-se quantificar o total de vítimas atendidas, assim como todas as despesas demandadas para proporcionar os serviços de atendimento pré-hospitalar prestados, envolvendo desde a solicitação até o encerramento da ocorrência, e a estrutura necessária para garantir a continuidade do serviço.

$A$ visão contábil do custo do atendimento às vítimas pode auxiliar o poder público, as organizações envolvidas e a própria sociedade, na tomada de decisões referente às demandas necessárias para a oferta desse serviço de socorro público. Ainda, possibilita dar ciência aos envolvidos e interessados sobre o custo específico devido à natureza da demanda, e para instigar a sociedade a buscar maior conscientização sobre a questão, perante os valores envolvidos e os reflexos benéficos de uma prevenção mais ativa.

$\mathrm{Na}$ busca dos dados para fomentar o presente trabalho, foi empregada a pesquisa documental, com levantamento de dados no setor de finanças e logística do Corpo de Bombeiros de Toledo - PR, buscando identificar as despesas custeadas pelo município, envolvidas no atendimento às vítimas e demandadas no serviço prestado na unidade. Ainda foram pesquisados dados de acesso público disponíveis na internet referentes a despesas custeadas 
pelo Governo Estadual, e por fim, buscaram-se dados sobre quantitativo de vítimas, nos sistemas de registros próprios do Corpo de Bombeiros do Paraná.

\section{DESENVOLVIMENTO}

\subsection{Contabilidade Pública}

Desde os primórdios das relações comerciais entre os homens, houve a necessidade de mensurar suas movimentações financeiras, seja por controle do Estado, seja pela necessidade de sobrevivência familiar, ou ainda, pelo ímpeto despertado devido aos lucros auferidos.

De acordo com ludícibus (2010) a contabilidade na sua concepção de ciência social aplicada, abrange uma vasta gama de interessados, sejam estes públicos ou privados, devido sua característica própria de captar, registrar, acumular, resumir e interpretar os fenômenos que interagem com pessoas jurídicas ou físicas, tanto no viés econômico, financeiro ou patrimonial.

$\mathrm{Na}$ administração pública muitos dos conceitos tradicionais no meio privado tem um tratamento específico não somente para se adequar à legislação pertinente, mas principalmente para atender ao fim que se destina, ou seja, permitir a gestão e a prestação de serviço público.

Nesse sentido, observamos que o objetivo primordial da contabilidade aplicada ao setor público, segundo Assumpção (2007), é ser o meio informativo, para demonstrar a situação financeira, contábil e patrimonial da organização, além de cumprir as exigências legais que devem ser obrigatoriamente observadas pelo órgão público.

Ainda no intuito de destacar o viés da contabilidade atrelado ao setor público, Araújo e Arruda (2020, p. 13) a consideram "um sistema de informações voltado a selecionar, registrar, resumir, interpretar e divulgar os fatos mensuráveis em moeda, que afetam as situações patrimoniais, financeiras e orçamentárias de órgãos e entidades públicos". 
Fica amplamente evidenciada pela teoria que relaciona a contabilidade à área pública, a atenção e a preocupação em se demonstrar de forma clara, correta e detalhada as informações pertinentes as finanças, devido à responsabilidade legal inerente à questão e ao controle necessário sobre tais fatos contábeis.

Ainda, para auxiliar no entendimento da teoria contábil, cabe mencionar outro ramo da Contabilidade Geral, ou seja, a Contabilidade de Custos, a qual visa identificar quais são os gastos realizados por uma organização no decorrer do desenvolvimento de suas atividades, a fim de possibilitar a oferta de seus produtos ou serviços no mercado, analisando e acompanhando seus comportamentos (SCHULTZ, 2019).

O custo pode ser então considerado como o esforço empregado pela empresa na busca de seus objetivos, pois conforme Martins (2010, p. 17), custo é o "gasto relativo ao bem ou serviço utilizado na produção de outros bens ou serviços".

Em suma, trata-se de organizar os gastos com matéria-prima, recursos humanos, aluguel, energia, água, combustível, manutenção, equipamentos e outros insumos demandados nas atividades diárias da organização, possibilitando o desenvolvimento de suas operações e consequentemente 0 retorno pretendido.

Percebe-se pelo foco da contabilização de custos que, de forma geral, sua aplicação está voltada para as operações ou movimentações contábeis das organizações privadas, porém tal fato não impede seu emprego nas organizações com características diversas, com as devidas adaptações, proporcionando grande colaboração no levantamento dos custos de ordem pública, por exemplo.

A partir do conhecimento e gestão dos custos, possibilitam-se diagnosticar resultados e fomentar tomada de decisões, primordiais para a manutenção saudável das atividades das organizações, sejam estas privadas ou públicas. 
Na sequência do desmembramento teórico, cabe abordar o conceito de Despesa Pública ao mencionar a importância da correta aplicação dos valores arrecadados pelo ente público, via cobrança de impostos e outras fontes, visando o custeio das demandas sociais de responsabilidade pública, e ainda, na realização de investimentos para prover e melhorar a estrutura que comporta tais demandas.

Reiterando o conceito desse tipo de despesa, Araújo e Arruda (2020, p. 138) mencionam que "a despesa pública também pode ser definida como o conjunto de dispêndios realizados pelos entes públicos para o funcionamento e a manutenção dos serviços públicos prestados à sociedade".

A partir de tal arcabouço teórico, buscou-se neste trabalho evidenciar o viés contábil envolvido no serviço de atendimento às vítimas realizado pelo Corpo de Bombeiros de Toledo, por meio das despesas englobadas, possibilitando apontar informações a respeito do custo final de um serviço público específico e de vital importância para a sociedade.

\subsection{Corpo de Bombeiros de Toledo-PR e o Atendimento Pré-Hospitalar}

A organização abordada no presente estudo é uma das unidades do Corpo de Bombeiros Militar do Paraná, integrante da Secretaria Estadual da Segurança Pública (SESP). Trata-se do Corpo de Bombeiros de Toledo, município situado na Região Oeste do Estado. Denominado Segundo Subgrupamento de Bombeiros, o Corpo de Bombeiros de Toledo foi fundado no ano de 1983 passando a compor uma subunidade do Quarto Grupamento de Bombeiros (Cascavel-PR), tendo sua área de atuação definida no entorno de sua sede, sendo responsável pelo atendimento de ocorrências em 10 municípios (CORPO DE BOMBEIROS DO PARANÁ, 2020a), abrangendo uma área de $4.192 \mathrm{~km}^{2}$ a qual soma uma população de 225.052 habitantes $^{2}$ (IBGE, 2021).

\footnotetext{
${ }^{2}$ População estimada para 2020, conforme dados do IBGE.
} 
$\mathrm{O}$ atendimento às vítimas envolvidas nos mais diversos acidentes faz parte da incumbência dos serviços prestados pelo Corpo de Bombeiros, competência definida em lei com embasamento na legislação federal e estadual. A Constituição Federal menciona no artigo 144 "A segurança pública, dever do Estado, direito e responsabilidade de todos, é exercida pela preservação da ordem pública e da incolumidade das pessoas e do patrimônio" (BRASIL, 1988), sendo um de seus órgãos os corpos de bombeiros militares com suas atribuições definidas em lei própria.

No Paraná a Lei Estadual № 16.575 de 2010, em seu artigo 2ํdefine as competências das Organizações Militares do Estado do Paraná, sendo descrito no parágrafo IV a competência entendida como específica do Corpo de Bombeiros, ou seja, "realizar serviços de busca, salvamento, prevenção e combate a incêndio" (PARANÁ, 2010).

Confirmando a busca do aprimoramento dos serviços prestados na área de atendimento às vítimas, o Corpo de Bombeiros do Paraná inaugurou no ano de 1990 um novo formato de atendimento pré-hospitalar no Brasil, com a implantação do Sistema Integrado de Atendimento ao Trauma e Emergência, conhecido pela sigla SIATE, contemplando inicialmente somente o município de Curitiba (PARANÁ, 2015).

Ao longo dos anos o serviço foi expandido para as grandes cidades do Estado, as quais comportam a estrutura necessária, como médicos e hospitais conveniados. Em Toledo não houve a implantação do SIATE, porém a estrutura disponível no Corpo de Bombeiros do município para o atendimento pré-hospitalar, indubitavelmente é reflexo da evolução que o SIATE proporcionou.

Após o advento do sistema, foi possível a disseminação de técnicas, protocolos, treinamentos, equipamentos e outros fatores que contribuem na melhoria da prestação desses serviços em todo o Estado do Paraná. Todas as unidades do Corpo de Bombeiros acabam sendo beneficiadas de alguma forma pelo sistema, a exemplo da unidade de Toledo que conta com bombeiros 
Revista Científica do Corpo de Bombeiros Militar de Pernambuco

Artigo Publicado no Vol.07 N.19 - Julho a Dezembro 2021 - ISSN 2359-4829

Versão on-line disponível em: http://www.revistaflammae.com

formados no curso de socorrista, equipamentos e ambulâncias no padrão do SIATE, apesar do município não contar com sua implantação.

\subsection{Custo do Atendimento às Vítimas}

A partir de todo arcabouço explicitado e após o levantamento de dados pertinentes concluído, chega-se ao ponto principal deste estudo, demonstrar pelo viés contábil o custo do atendimento às vítimas "socorridas" pelo Corpo de Bombeiros de Toledo, abrangendo todas as ocorrências do ano de 2019, nas quais houve necessidade de intervenção dos bombeiros socorristas.

A partir dos dados armazenados no Sistema de Registro de Ocorrências e Estatísticas do Corpo de Bombeiros do Paraná (SYSBM), verificou-se que as ocorrências com registro de vítimas estão divididas por suas naturezas, definidas como "Atendimento Pré-Hospitalar" (APH), "Acidentes de Trânsito", "Atendimento Comunitário", "Busca e Salvamento", "Desastre" e "Incêndio". Conforme a Tabela 01, dentre tais ocorrências registradas pelo Quartel Central e pelo Posto Satélite, unidades do Corpo de Bombeiros de Toledo, no total foram atendidas 2.774 vítimas no ano de 2019 (CORPO DE BOMBEIROS DO PARANÁ, 2020b).

TABELA 01 - VÍTIMAS ATENDIDAS PELO CORPO DE BOMBEIROS DE TOLEDO NO ANO DE 2019.

\begin{tabular}{c|c|c}
\hline \multicolumn{3}{c}{ Vítimas Atendidas - Bombeiros Toledo - 2019 } \\
\hline Unidade & Vítimas Atendidas & $\%$ \\
\hline Quartel Central/Toledo & 1601 & 57,71 \\
\hline Posto Satélite/Toledo & 1173 & 42,29 \\
\hline TOTAL & $\mathbf{2 7 7 3}$ & $\mathbf{1 0 0 , 0 0}$ \\
\hline
\end{tabular}

FONTE: CORPO DE BOMBEIROS DO PARANÁ - SYSBM (2020).

No somatório das despesas elencadas para compor o custo pretendido, foram agrupados os elementos que formam cada item essencial à prestação do serviço de atendimento às vítimas, sendo neste estudo definidos como: 
- Viaturas (combustível, manutenção, seguro, documentação, depreciação);

- Recursos humanos (folha de pagamento, alimentação, fardamento);

- Material APH consumo (material para curativos e imobilizações, oxigênio, equipamento de proteção individual, outros);

- Material APH reutilizável (tábua de imobilização, colar cervical, imobilizador de cabeça, aferidor de pressão, oxímetro, outros);

- Serviços de apoio (energia elétrica, água e esgoto, telefone e internet).

Para cada elemento que compõe o custo, foram levantados os dados relativos a todo o ano de 2019, sendo que no grupo "viaturas" foram relacionadas as despesas com a frota de ambulâncias empregadas no atendimento às vítimas. Tal frota era composta de três viaturas tipo Auto Ambulância ( $A A)$, sendo uma ambulância empregada no Quartel Central, uma no Posto Satélite, e ainda, uma ambulância permanecia como viatura reserva, caso alguma das outras necessitasse ser substituída eventualmente por problemas mecânicos ou outro motivo.

Cada uma das ambulâncias recebe um prefixo para sua identificação, registro e gestão operacional. No ano de 2019, a frota em questão era composta pelas ambulâncias de prefixo e marca/modelo conforme segue:

- AA 9704 (FIAT/Ducato, ano 2011);

- AA 10863 (MERCEDES BENZ/415, ano 2012);

- AA 11529 (RENAULT/Master, ano 2016).

Os dados referentes às despesas com os veículos foram obtidos por meio de levantamento no setor financeiro da unidade em questão, englobando despesas realizadas com manutenção de frota, seguro, documentação e produtos para limpeza das viaturas. Ainda foram utilizados dados da Fundação Instituto de Pesquisas Econômicas (FIPE) referente ao preço médio dos veículos (FIPE, 2020) para definir os valores de 
Revista Científica do Corpo de Bombeiros Militar de Pernambuco

Artigo Publicado no Vol.07 N.19 - Julho a Dezembro 2021 - ISSN 2359-4829

Versão on-line disponível em: http://www.revistaflammae.com

depreciação deles, e, dados do sistema de gestão do abastecimento, para identificar as despesas referentes ao combustível consumido no período em questão. Na Tabela 02 estão expostas as despesas demandadas pela frota de ambulâncias do Corpo de Bombeiros de Toledo.

TABELA 02 - DESPESAS COM VIATURAS TIPO AMBULÂNCIA NO CORPO DE BOMBEIROS DE TOLEDO NO ANO DE 2019. Despesas Viaturas/Ambulâncias - Bombeiros Toledo - 2019

\begin{tabular}{c|r|r}
\hline Tipo Despesa & Valor (R\$) & \multicolumn{1}{|c}{$\%$} \\
\hline Manutenção & $29.180,05$ & 44,94 \\
\hline Combustível & $23.494,44$ & 36,18 \\
\hline Depreciação & $6.158,00$ & 9,48 \\
\hline Seguro Privado & $5.633,90$ & 8,68 \\
\hline Documentação & 308,51 & 0,48 \\
\hline Material de Limpeza & 154,80 & 0,24 \\
\hline TOTAL & $\mathbf{6 4 . 9 2 9 , 7 0}$ & $\mathbf{1 0 0 , 0 0}$
\end{tabular}

FONTE: DADOS DA PESQUISA (2020).

Quanto aos recursos humanos empregados nos serviço de atendimento às vítimas, as informações sobre despesas inerentes foram divididas em folha de pagamento dos bombeiros militares, valores gastos com a alimentação necessária nos dias de plantão desses militares, e ainda a despesa com os uniformes utilizados, ou seja, o fardamento militar, necessário à caracterização do bombeiro militar, assim como para sua proteção durante a prestação dos serviços.

Para este estudo foram considerados somente os dados sobre folha de pagamento dos bombeiros que atuaram diretamente na operacionalização do serviço de atendimento pré-hospitalar, sendo incluídos os dados dos bombeiros escalados nas ambulâncias e na função de radioperador/atendente, somando em média sete bombeiros por dia de serviço. Ainda, no registro da despesa com fardamento foi considerada a necessidade das peças do uniforme que mais sofrem desgaste pelo uso e limpeza (um conjunto de calça e camisa Ripstop, uma camiseta vermelha) 
Revista Científica do Corpo de Bombeiros Militar de Pernambuco

Artigo Publicado no Vol.07 N.19 - Julho a Dezembro 2021 - ISSN 2359-4829

Versão on-line disponível em: http://www.revistaflammae.com

para cada bombeiro no período em questão. Os dados referentes às despesas com recursos humanos são apresentados na Tabela 3.

\section{TABELA 03 - DESPESAS COM RECURSOS HUMANOS NO CORPO DE} BOMBEIROS DE TOLEDO NO ANO DE 2019.

\begin{tabular}{c|c|r}
\hline \multicolumn{4}{c}{ Recursos Humanos - Bombeiros Toledo -2019} \\
\hline Tipo Despesa & Valor $(\mathrm{R} \$)$ & $\%$ \\
\hline Folha de Pagamento & $1.436 .405,44$ & 89,97 \\
\hline Alimentação & $157.740,45$ & 9,88 \\
\hline Fardamento & $2.423,59$ & 0,15 \\
\hline TOTAL & $\mathbf{1 . 5 9 6 . 5 6 9 , 4 8}$ & $\mathbf{1 0 0 , 0 0}$ \\
\hline
\end{tabular}

FONTE: DADOS DA PESQUISA (2020).

Observando os dados da Tabela 03, percebemos a relevância da participação da folha de pagamento na composição das despesas com recursos humanos, empregados diretamente no serviço de atendimento às vítimas.

As despesas referentes ao material de APH de consumo englobam os materiais empregados para contenção de hemorragias, imobilização de membros, oxigenação da vítima, material para proteção dos socorristas, formulários para anotações de dados das vítimas e demais informações, produtos para assepsia dos materiais de APH e do salão de atendimento, e demais materiais pertinentes.

$\mathrm{Na}$ Tabela 4 estão descritas tais despesas, observando que tais itens caracterizam-se como materiais de consumo por serem descartados após 0 uso ou pelo seu consumo propriamente na utilização. 
Revista Científica do Corpo de Bombeiros Militar de Pernambuco

Artigo Publicado no Vol.07 N.19 - Julho a Dezembro 2021 - ISSN 2359-4829

Versão on-line disponível em: http://www.revistaflammae.com

\section{TABELA 04 - DESPESAS COM MATERIAL DE ATENDIMENTO PRÉ- HOSPITALAR DE CONSUMO NO CORPO DE BOMBEIROS DE TOLEDO NO ANO DE 2019.}

\begin{tabular}{c|c|c}
\hline \multicolumn{3}{c}{ Material APH Consumo - Bombeiros Toledo - 2019} \\
\hline Tipo Despesa & Valor $(\mathrm{R} \$)$ & $\%$ \\
\hline $\begin{array}{c}\text { Equipamento de proteção } \\
\text { individual }\end{array}$ & $10.539,50$ & 31,45 \\
\hline Material para curativos & $6.673,90$ & 19,91 \\
\hline Produtos para assepsia & $5.190,30$ & 15,49 \\
\hline Materiais diversos & $4.988,50$ & 14,88 \\
\hline Oxigênio & $2.925,00$ & 8,73 \\
\hline Material para imobilização & $1.620,00$ & 4,83 \\
\hline Material para anotações & $1.577,00$ & 4,71 \\
\hline TOTAL & $\mathbf{3 3 . 5 1 4 , 2 0}$ & $\mathbf{1 0 0 , 0 0}$ \\
\hline
\end{tabular}

FONTE: DADOS DA PESQUISA (2020).

Quanto ao material de atendimento pré-hospitalar reutilizável, foram elencados os materiais que são empregados no atendimento às vítimas e que posteriormente retornam a unidade para limpeza e desinfecção, se tornando novamente disponíveis para uso. Dentre tais materiais estão o aparelho de medir pressão digital, cinto de imobilização, colar cervical, esfigmomanômetro e estetoscópio, imobilizador de cabeça, oxímetro portátil digital, reanimador "ambu", tábua de imobilização e o tracionador de fêmur.

Nesse tópico foram levantadas informações a respeito da consumição e/ou extravio desse tipo de materiais, a fim de se mensurar monetariamente quanto se consome no período de um ano de cada um dos itens em questão. Para compor tal informação foi verificado o valor de cada material na época definida para o presente estudo, e ainda se realizou um levantamento entre os bombeiros que atuam diretamente no emprego, recolhimento e assepsia de tais materiais, sobre as quantidades de material inutilizado ou extraviado anualmente.

A partir da compilação dos dados mencionados, verificou-se que a despesa gerada pela consumição ou extravio dos materiais de atendimento pré-hospitalar reutilizáveis no ano de 2019 , alcançou o valor de $R \$ 4.116,90$, considerando todas as perdas nesse quesito. 
Revista Científica do Corpo de Bombeiros Militar de Pernambuco

Artigo Publicado no Vol.07 N.19 - Julho a Dezembro 2021 - ISSN 2359-4829

Versão on-line disponível em: http://www.revistaflammae.com

A demanda por serviços de apoio, aqui considerados como os serviços necessários para o funcionamento da estrutura física da organização (Tabela 5), também faz parte da formação do custo elencado como objetivo do estudo.

TABELA 05 - DESPESAS COM SERVIÇOS DE APOIO NO CORPO DE
BOMBEIROS DE TOLEDO NO ANO DE 2019.
\begin{tabular}{c|c|r}
\hline \multicolumn{2}{c}{ Serviços de Apoio - Bombeiros Toledo - 2019 } \\
\hline Tipo Despesa & Valor (R\$) & $\%$ \\
\hline Energia elétrica & $25.078,22$ & 51,54 \\
\hline Água e esgoto & $12.800,22$ & 26,31 \\
\hline Internet & $7.020,72$ & 14,43 \\
\hline Telefonia & $3.754,05$ & 7,72 \\
\hline TOTAL & $\mathbf{4 8 . 6 5 3 , 2 0}$ & $\mathbf{1 0 0 , 0 0}$ \\
\hline
\end{tabular}

FONTE: DADOS DA PESQUISA (2020).

Para tal levantamento foram pesquisadas as contas mensais de cada serviço em questão, utilizando aqui as frações dessas despesas, consideradas proporcionais às necessidades do serviço que envolva o atendimento às vítimas, desenvolvido na organização.

Por fim, reuniu-se o total das despesas envolvidas diretamente no atendimento às vítimas pelo Corpo de Bombeiros de Toledo, valores esses que quando relacionados com o total de vítimas atendidas no ano de 2019, possibilitam identificar de forma geral o custo por vítima, conforme Tabela 06, informação que resume o alcance do objetivo específico aqui proposto.

\begin{tabular}{|c|c|c|c|}
\hline \multicolumn{4}{|c|}{$\begin{array}{l}\text { TABELA } 06 \text { - DESPESAS DEMANDADAS PELO ATENDIMENTO ÀS } \\
\text { víTIMAS NO CORPO DE BOMBEIROS DE TOLEDO NO ANO DE } 2019 . \\
\text { Despesas com atendimento às vítimas - Bombeiros Toledo - } 2019\end{array}$} \\
\hline Tipo Despesa & $\begin{array}{l}\text { Valor Total } \\
(\mathrm{R} \$)\end{array}$ & $\begin{array}{c}\text { Valor Unitário } \\
(\mathrm{R} \$)\end{array}$ & $\%$ \\
\hline Recursos Humanos & $1.596 .569,48$ & 575,55 & 91,35 \\
\hline Viaturas & $64.929,70$ & 23,41 & 3,71 \\
\hline Serviços de Apoio & $48.653,20$ & 17,54 & 2,78 \\
\hline $\begin{array}{l}\text { Material APH } \\
\text { Consumo }\end{array}$ & $33.514,20$ & 12,08 & 1,92 \\
\hline $\begin{array}{c}\text { Material APH } \\
\text { Reutilizável }\end{array}$ & $4.116,90$ & 1,48 & 0,24 \\
\hline TOTAL & $1.747 .783,48$ & 630,06 & 100,00 \\
\hline
\end{tabular}

FONTE: DADOS DA PESQUISA (2020). 
Ao final da compilação dos dados verificou-se que as despesas geradas em virtude dos serviços prestados pelo Corpo de Bombeiros de Toledo, em função das 2.774 vítimas atendidas no ano de 2019, somaram um custo total de $R \$ 1.747 .783,48$. A partir dessas informações é possível identificar o custo médio por vítima atendida, que registrou o valor de $\mathrm{R} \$ 630,06$. Salienta-se que o valor corresponde a uma média geral, independente da gravidade de lesões, risco de vida apresentado, distância percorrida ou qualquer outro fator específico de cada ocorrência.

\section{CONCLUSÃO}

Após a consecução do objetivo do presente estudo, percebe-se a envergadura organizacional necessária para possibilitar o serviço final de atendimento às vítimas, desempenhado pelo Corpo de Bombeiros do Paraná, aqui representado pela unidade localizada no município de Toledo. $\mathrm{O}$ ambiente escolhido para a realização do trabalho justifica sua importância pela especificidade do serviço público prestado à sociedade, sendo que, para o período definido como o intervalo a ser estudado, o ano de 2019, foi registrado um total de 2.774 vítimas atendidas, o que significa uma média de 7 vítimas por dia, demandando o serviço de atendimento pré-hospitalar proporcionado pelo Corpo de Bombeiros de Toledo.

No decorrer da abordagem teórica se observou que o arcabouço da Contabilidade Pública é um tanto incipiente, porém já amplamente definido em normas legais e observado pelo poder público, o qual tem o dever de seguir seus preceitos. Entendendo que a grande parte dos dados pesquisados estaria alinhada com o conceito de Despesa Pública, foi possível identificar e enumerar todas as despesas consideradas pertinentes na busca da mensuração contábil do custo do atendimento às vítimas. 
Com os critérios de pesquisa definidos e concluídos os trabalhos de processamento dos dados, identificaram-se as despesas com participação na formação do custo final, as quais foram divididas em grupos englobando viaturas, recursos humanos, materiais de APH e os serviços de apoio. Nota-se que a despesa com maior impacto no custo final é a que envolve os recursos humanos, denotando sua importância e refletindo sua relevância como fator crucial no serviço prestado. Apesar da necessidade de todo conjunto de fatores, sem contar com pessoal especializado, preparado e disponível constantemente, não seria possível atingir a qualidade esperada e necessária a um serviço de extrema importância, como o é o atendimento pré-hospitalar.

Cabe reiterar que o estudo foi realizado com as devidas autorizações para a coleta de dados, e que os valores das despesas incluídas na constituição do custo do serviço abordado são reais e fidedignos, cabendo ao autor definir a razão de participação de cada tipo de despesa na formação desse custo, em virtude do Corpo de Bombeiros de Toledo abranger diversas outras atividades.

Com a conclusão do trabalho identificou-se que a média geral do custo das vítimas atendidas pelo Corpo de Bombeiros de Toledo no ano de 2019, registrou um valor de $\mathrm{R} \$ 630,06$ por vítima. O resultado da pesquisa desenvolvida e das informações proporcionadas revela a face contábil e monetária do serviço prestado, assim como a participação de cada fator no custo final. $O$ intuito principal da demonstração das informações contábeis aqui geradas não é, de forma alguma, precificar o serviço, pois o bem a ser resguardado é inestimável. A pretensão maior ao término desse estudo é colaborar com a administração do órgão público, no sentido de otimizar o emprego do patrimônio e da verba pública, buscando fornecer sempre um serviço de qualidade, visando a incolumidade do bem mais precioso bem a ser resguardado, a vida humana. 


\section{REFERÊNCIAS}

ARAÚJO, Inaldo; ARRUDA, Daniel. Contabilidade pública: da teoria à prática. 3. ed. São Paulo: Saraiva, 2020.

ASSUMPÇÃO, M. J. Contabilidade pública. Curitiba: Ibpex, 2007.

BRASIL. Constituição (1988). Constituição da República Federativa do Brasil, 1988. Artigo 144 da Constituição Federal. Disponível em: < http://www.planalto.gov.br/ccivil_03/constituicao/constituicao.htm>, Acesso em: 20 nov. 2020.

CORPO DE BOMBEIROS DO PARANÁ. 4 Grupamento de Bombeiros / Cascavel - área de atuação. Disponível em: $<$ http://www.bombeiros.pr.gov.br/4gb/Pagina/Area-de-Atuacao-4o-GBCascavel>, Acesso em: 10 nov. 2020a.

CORPO DE BOMBEIROS DO PARANÁ. Sysbm. Disponível em: <http://www.sysbm.bombeiros.pr.gov.br/sysbmnew/menu/>, Acesso em: 10 nov. 2020b.

FIPE - FUNDAÇÃO INSTITUTO DE PESQUISAS ECONÔMICAS. Índices e indicadores - preço médio de veículos. Disponível em: $<$ https://veiculos.fipe.org.br/>, Acesso em: 10 out. 2020.

IBGE - INSTITUTO BRASILEIRO DE GEOGRAFIA E ESTATÍSTICA. @cidades. Disponível em: <https://cidades.ibge.gov.br/>, Acesso em: 10 jan. 2021.

IUDíCIBUS, Sérgio de. et al. Contabilidade introdutória. 11 ed. São Paulo: Atlas, 2010.

MARTINS, Eliseu. Contabilidade de Custos. 9 ed. São Paulo: Atlas, 2010. 
PARANÁ. Lei no 16.575 , de 28 de setembro de 2010. Dispõe sobe a destinação da Polícia Militar do Estado do Paraná. Disponível em: < https://www.legislacao.pr.gov.br/legislacao/listarAtosAno.do?action=exibir\&cod Ato $=56275$ indice $=5 \&$ total Registros $=418 \&$ anoSpan $=2011$ \&anoSelecionado $=20$ 10\&mesSelecionado=0\&isPaginado=true $>$, Acesso em: 22 nov. 2020.

PARANÁ. Agência Estadual de Notícias, 18 de maio de 2015. Siate do Paraná comemora $\mathbf{2 5}$ anos com mais de $\mathbf{3 0 0}$ mil ocorrências atendidas. Disponível em:

http://www.aen.pr.gov.br/modules/noticias/article.php?storyid=84162\&tit=Siatedo-Parana-comemora-25-anos-com-mais-de-300-mil-ocorrenciasatendidas\&ordem $=30>$, Acesso em: 25 nov. 2020.

SCHULTZ, Felix. BomControle - Artigos, 18 de março de 2019. Contabilidade de Custos: Entenda o que é e como usa na sua empresa. Disponível em: $<$ https://bomcontrole.com.br/contabilidade-de-custos/>, Acesso em: 10 jan. 2021. 